\title{
Efficiency of modified Goldman's technique in open pediatric septoplasty
}

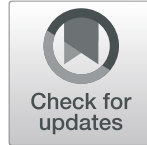

Omar Sabry, Hazem Dewidar, Mosaad abdel Aziz, Amr Elemam and Ahmed Nassar * (D)

\begin{abstract}
Background: Performing nasal surgery on children has been the subject of controversy among surgeons. Specifically, the indications for and timing of septoplasty in children have been debated for the last several decades.

In this study, we access the efficacy of the modified Goldman's technique in dealing with caudal septal deviation in pediatric population suffering from severe nasal obstruction and its effect on nasal functions postoperatively. In this study, 30 pediatric patients suffering from deviated nasal septum who are candidate for septoplasty were included and underwent open septoplasty using modified Goldman's technique.

They were subjected to detailed assessment protocol preoperatively including NOSE scale, anterior rhinomanometry, and CT scans. Follow-up assessment was done at second week postoperative including anterior rhinoscopy and nasal endoscopy and 3 months postoperative including NOSE scale and anterior rhinomanometry.

Results: There was a statistically significant decrease of the NOSE scale severity to none in $90 \%$ of cases. Three months postoperative, all of the patients performed postoperative anterior active rhinomanometry with statistically significant decrease in the postoperative total nasal resistance values with inspiratory values ranging from 0.1 to 0.5 $\mathrm{Pa} / \mathrm{cm}^{3} / \mathrm{s}$ with mean of $0.26 \mathrm{~Pa} / \mathrm{cm}^{3} / \mathrm{s}$ and expiratory nasal resistance values ranging from 0.1 to $0.6 \mathrm{~Pa} / \mathrm{cm}^{3} / \mathrm{s}$ with mean of $0.31 \mathrm{~Pa} / \mathrm{cm}^{3} / \mathrm{s}$.

Conclusions: Open septoplasty in children using the modified Goldman's technique has enabled accurate and conservative approach for correction of nasal septal deviation especially those located in the caudal septal region. The technique also offers a significant reduction of the nasal symptoms postoperatively with marked improvement of the nasal resistance and quality of life in severe cases of deviated nasal septum.
\end{abstract}

Keywords: Open septoplasty, Pediatric septoplasty, Modified Goldman's technique

\section{Background}

Although septoplasty is commonly performed in adults, it is not routinely performed in the pediatric population. The backing down to perform septoplasty in pediatric patients is related to concerns over adverse effects on nasal and facial growth [1].

Performing nasal surgery on children has been the subject of controversy among surgeons. Specifically, the indications for and timing of septoplasty in children have been debated for the last several decades.

\footnotetext{
*Correspondence: Ahmednassar_79@hotmail.com

Otolaryngology Department, Cairo University, Cairo 11734, Egypt
}

Pediatric septoplasty associated problems regarding nasal and facial growth was a controversy for many decades. In the 1950s, Gilbert and Segal referred to the quadrilateral cartilage as a keystone in development of the nasal vault and a further literature review in the 1970s stated that nasal surgery should be postponed till puberty [1-3].

However, later studies postulate that septal surgery does not delay nasal or facial growth. Furthermore, evidence is available which states that delaying septal surgery in children can lead to more complication as facial abnormalities, dental malocclusion, and respiratory morbidity [4, 5]. Therefore, not performing septal

\section{Springer Open}

(๑) The Author(s). 2021 Open Access This article is licensed under a Creative Commons Attribution 4.0 International License, which permits use, sharing, adaptation, distribution and reproduction in any medium or format, as long as you give appropriate credit to the original author(s) and the source, provide a link to the Creative Commons licence, and indicate if changes were made. The images or other third party material in this article are included in the article's Creative Commons licence, unless indicated otherwise in a credit line to the material. If material is not included in the article's Creative Commons licence and your intended use is not permitted by statutory regulation or exceeds the permitted use, you will need to obtain permission directly from the copyright holder. To view a copy of this licence, visit http://creativecommons.org/licenses/by/4.0/. 
surgery in children affected by septal deviation may be more problematic.

This article aims to assess the efficacy of the modified Goldman's technique in dealing with caudal septal deviation in pediatric population suffering from severe nasal obstruction and its effect on nasal functions postoperatively.

\section{Methods}

Prospective clinical study was conducted on 30 pediatric patients complaining of caudal septal deviation attending otolaryngology outpatient clinic, and the study was approved by the scientific and ethical committee of our institution.

\section{Study population}

Thirty patients were included in this study with age ranging from 5 to 17 years old.

\section{Inclusion criteria}

Patients less than 18 years old presenting with caudal septal deviation indicated for surgical intervention.

\section{Exclusion criteria}

- Previous history of nasal surgery
- Patient with posterior septal deviation

- Unfit for general anesthesia

- Associated nasal pathology as nasal polyps or chronic rhinosinusitis

- Congenital nasal deformities

\section{Preoperative assessment}

Full history is very important step in the evaluation of every patient presenting with deviated nasal septum including history of trauma, side of obstruction, severity of obstruction, nocturnal or constant obstruction, history of allergy and medication, and previous nasal surgery.

\section{Physical examination}

This was done for every patient by anterior rhinoscopy and nasal endoscopy to assess type of deviation and associated nasal pathology, e.g. turbinate hypertrophy and nasal polyps.

\section{Preoperative CT nose and paranasal sinus}

CT paranasal sinus axial and coronal views were performed to exclude associated nasal pathology (Fig. 1).

\section{Objective assessment}

Preoperative anterior active rhinomanometry (using the NR7 Rhinomanometry present in our institution) was
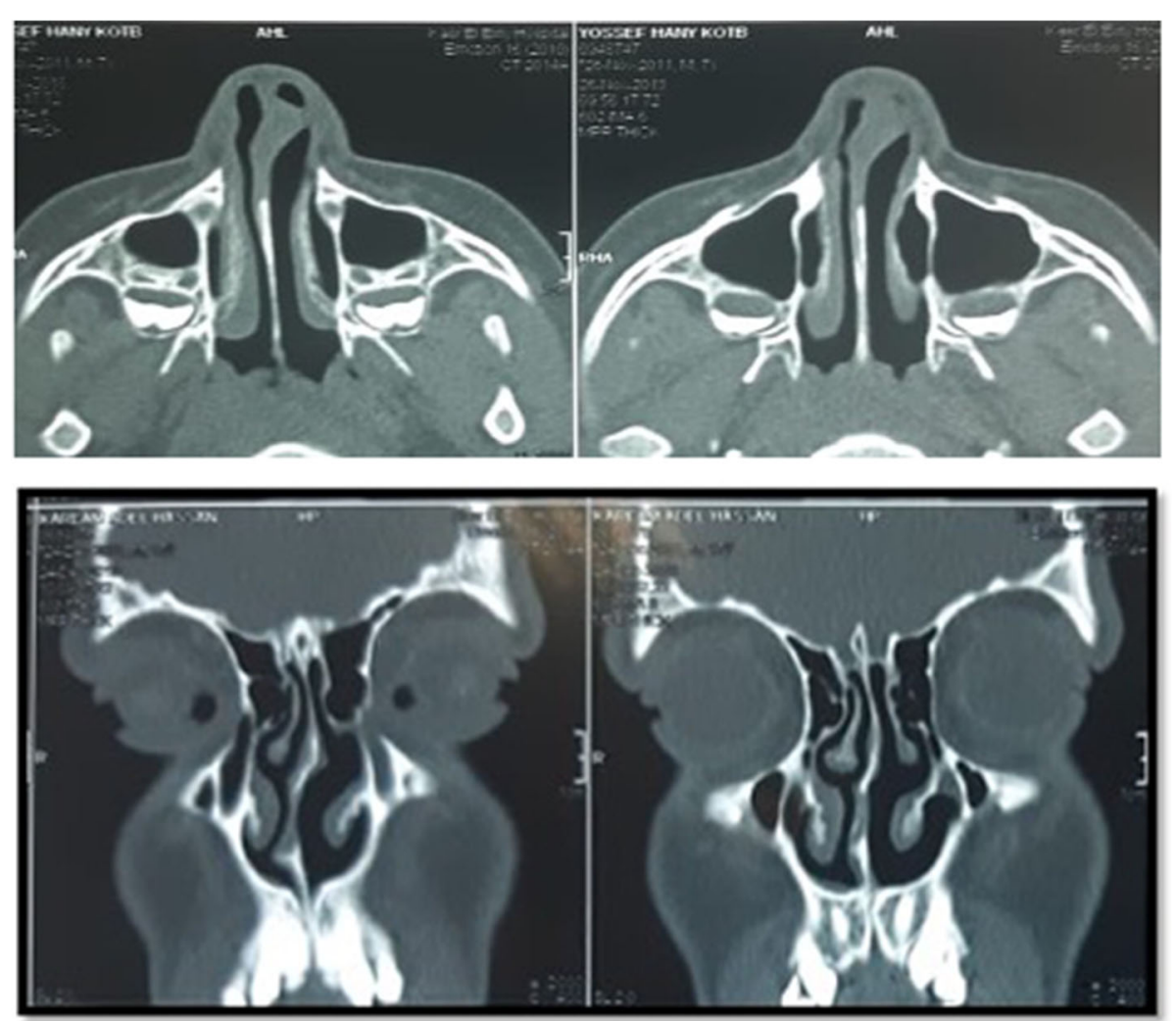

Fig. 1 CT (axial view and coronal views) of caudal septal deviation 


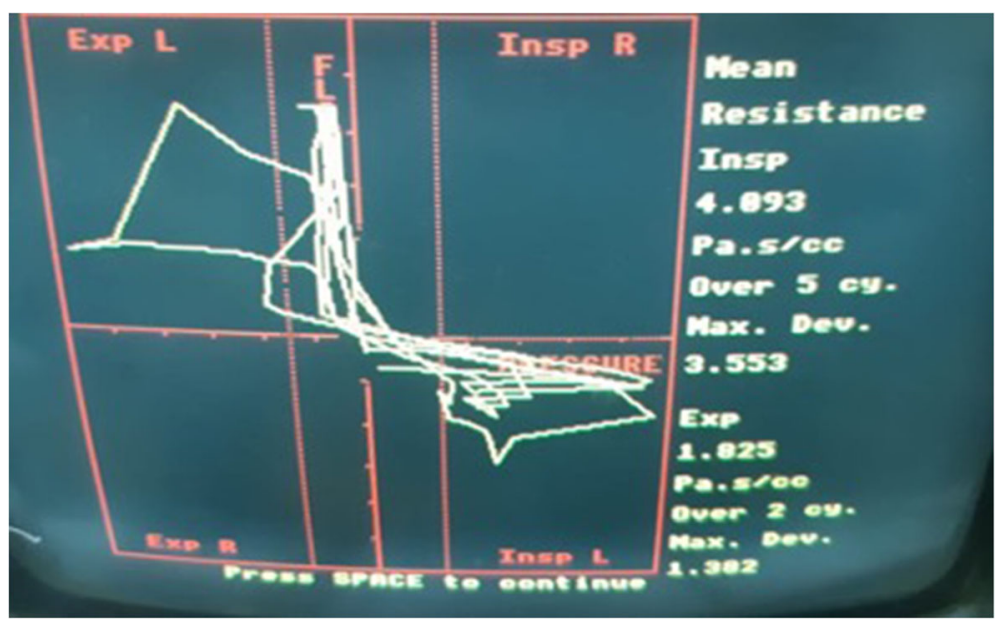

Fig. 2 Rhinomanomerty assessment to left nostril

done to every patient for objective assessment of nasal obstruction (Figs. 2 and 3).

\section{Subjective assessment}

We applied a modified scale using the nasal obstruction symptom evaluation (NOSE) scale set by Stewart et al. [6] and a $10-\mathrm{cm}$ visual analogue scale (VAS) for subjective assessment of severity of nasal obstruction and its impact on quality of life. The modified NOSE Scale consists of four items, each scored using a 5point symptom scale, with 0 meaning "not a problem" and 4 meaning "severe problem". The answers are then summed and multiplied by 5 for a final score out of 80. Higher scores indicate worse nasal obstruction. The severity of nasal obstruction was categorized as none (0-25), medium (26-55), and severe (56-80) (Fig. 4).

\section{Surgical procedure}

Modified Goldman's technique was performed following the guidelines set by Lawson and Westreich [7] including the following steps:
- Surgery was done under general hypotensive anesthesia with patient in supine position and head elevated $45^{\circ}$.

- Following intubation, the endotracheal tube is secured to the chin at midline to ensure accurate assessment of facial symmetry.

- Lubricant eye ointment is placed bilaterally, after which each eyelid is closed and secured using a transparent dressing.

- The caudal septum and nasal structures are injected with a solution of $1 \%$ lidocaine with 1:200,000 epinephrine in a sub-mucoperichondrial plane ideally resulting in hydro- dissection. Two $0.5 \times 3$-in. cottonoid pledges soaked with oxymetazoline are then placed in each nasal cavity.

- An inverted $\mathrm{V}$ incision is drawn at the narrowest point of the columella and a marginal incision is made with a 15 -mm blade.

- These scissors are then used to dissect the soft tissue away from the lower lateral and upper lateral cartilages to expose the caudal aspect of the septum and nasal dorsum. The nasal skin is retracted with an elevator.

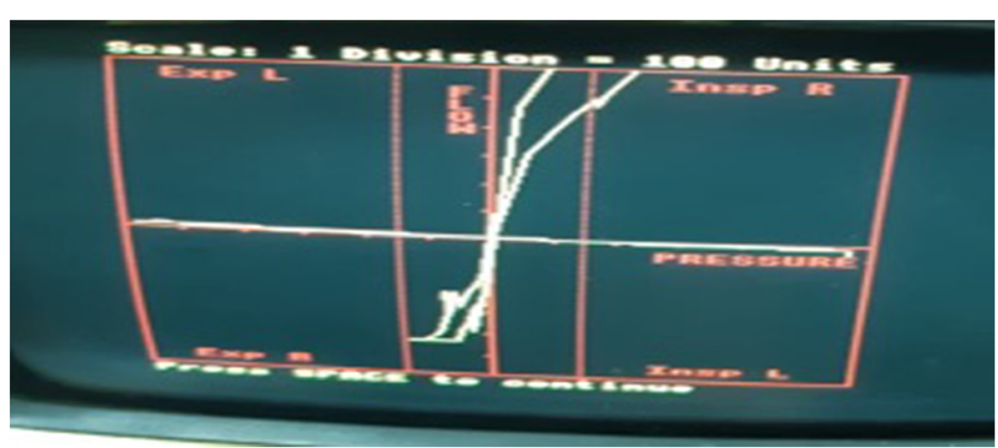

Fig. 3 Anterior rhinomanometry 

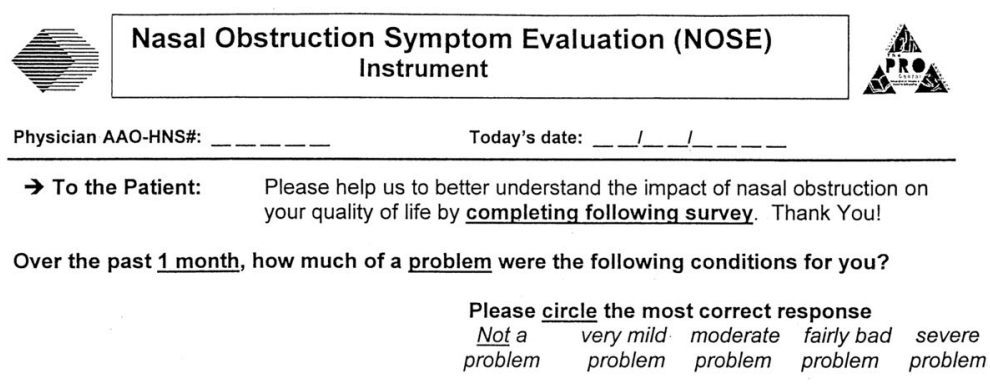

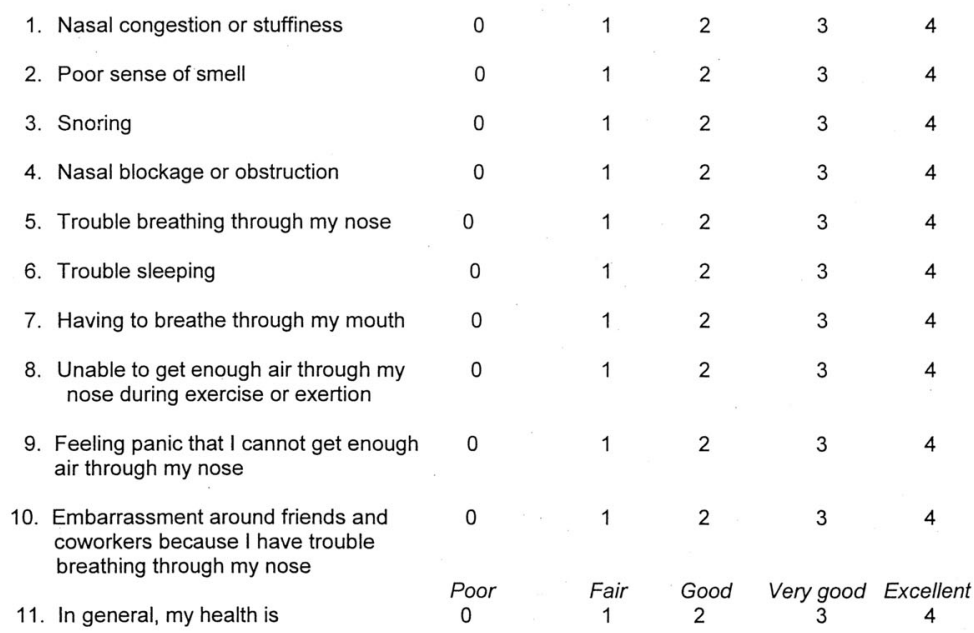

Please mark on this line how troublesome is your difficulty in breathing through your nose:

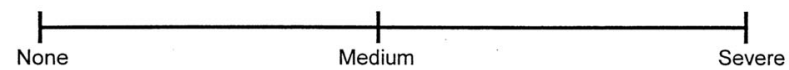

Fig. 4 Modified NOSE scale [6]

- The surgical technique consists of the dissection of the concave side of the perichondrium, preserving its convex side connected to the cartilage.

- To correct deviation, strips can be resected in vertical or horizontal direction.

- Closure of septo-collumellar incisions using PDS 4-0.

- Insertion of nasal packs and traditional plastic septal splints in both nostrils.

\section{Postoperative}

Medications including antibiotic (Amoxicillin-Clavulanic acid) and analgesic (Ibuprofen) were prescribed for 1 week. Adding alkaline nasal wash after removal of nasal packs for 2 weeks. Nasal packs were removed after $48 \mathrm{~h}$.

After 2 weeks postoperative included removal of septal splint, subjective assessment using NOSE scale, and physical examination, anterior rhinoscopy, and nasal endoscopy to detect residual septal deviation, nasal adhesions, septal hematoma, septal perforation, and external nasal deformity.

After 3 months postoperative included follow-up nasal endoscopy and objective assessment using anterior active rhinomanometry.

\section{Statistical methods}

Data were coded and entered using the statistical package SPSS (Statistical Package for the Social Sciences) version 25. Data was summarized using mean, standard deviation, median, minimum and maximum in quantitative data and using frequency (count) and relative frequency (percentage) for categorical data. For comparison of serial measurements (pre and post) within each patient, the non-parametric Wilcoxon signed rank test was used (Chan, 2003a). For comparing categorical data, chi-square $\left(x^{2}\right)$ test was performed. Exact test was used instead when the expected frequency is less than 5 (Chan, 2003b). $P$ values less than 0.05 were considered as statistically significant.

\section{Results}

The ages of our patients ranged from 5 to 17 years with mean age 12.7 years. Twenty-one patients were males (70\%) while 9 patients were females (30\%).

Preoperative endoscopic assessment was done to all patients with determination of nasal septal deviation type according to Mladina et al. [8] deviated nasal septum classification. Our results indicated that 12 
patients were suffering from type 1 deviated septum (40\%), 6 patients presented with type 2 (20\%), 6 patients with type 4 (20\%), and 3 patients with type $3(10 \%)$ while 3 patients with type $6(10 \%)$.

Preoperative anterior rhinomanometry was conducted on all patients with inspiratory total nasal resistance values ranging from 0.1 to $0.8 \mathrm{~Pa} / \mathrm{cm}^{3} / \mathrm{s}$ with mean of $0.4 \mathrm{~Pa} / \mathrm{cm}^{3} / \mathrm{s}$ and expiratory total nasal resistance values from 0.1 to $1 \mathrm{~Pa} / \mathrm{cm}^{3} / \mathrm{s}$ with mean of $0.5 \mathrm{~Pa} / \mathrm{cm}^{3} / \mathrm{s}$.

Correlation between preoperative NOSE scale severity and anterior rhinomanometry was done using Spearman correlation coefficient (Chan, 2003c). The formulas return a value between ( -1 and 1 ), where 1 indicates a strong positive relationship while -1 indicates a strong negative relationship. The absolute value of the correlation coefficient gives us the relationship strength. The larger the number, the stronger the relationship. Our results revealed a correlation coefficient of 0.49 for inspiratory values and 0.65 for expiratory values which is of moderate strength and the $P$ value was statistically significant only in the severity of the NOSE scale. These results signify the importance of objective assessment of nasal function using rhinomanometry preoperative in pediatric population.

\section{Surgeries were done according to the previously discussed methodology and went with no special events Subjective assessment 2 nd week postoperative}

Symptoms were recorded postoperative using NOSE scale as shown in. There was a statistically significant decrease of the NOSE scale severity to none in $90 \%$ of cases and mild obstruction in $10 \%$ of cases. Comparison was done between preoperative and postoperative with $P$ value less than 0.001 which is statistically significant.

Correlation between postoperative NOSE scale severity and anterior rhinomanometry revealed a correlation coefficient of 0.18 for inspiratory values and 0.28 for expiratory values which is of poor strength. The $P$ value was statistically significant only in (trouble breathing of the NOSE scale). These results signify the importance of objective assessment of nasal function using rhinomanometry postoperative in pediatric population

\section{Objective assessment 2nd week postoperative}

Endoscopic assessment using rigid nasal endoscopy $\left(0^{\circ}\right.$ angle endoscope) was performed to all patients to assess the presence of residual deviation, nasal adhesions, septal perforation, septal hematoma, or nasal deformity. Ten patients $(20 \%)$ were suffering from residual deviation while 5 patients $(10 \%)$ were complaining of external deformity and 1 patient (2\%) was suffering from nasal adhesions, and none of the patients suffer from septal perforation or septal hematoma (Fig. 5).

\section{Objective assessment 3 months postoperative}

All of the patients performed postoperative anterior active rhinomanometry with statistically significant decrease in the postoperative total nasal resistance values with inspiratory values ranging from 0.1 to 0.5 $\mathrm{Pa} / \mathrm{cm}^{3} / \mathrm{s}$ with mean of $0.26 \mathrm{~Pa} / \mathrm{cm}^{3} / \mathrm{s}$ and expiratory nasal resistance values ranging from 0.1 to $0.6 \mathrm{~Pa} /$ $\mathrm{cm}^{3} / \mathrm{s}$ with mean of $0.31 \mathrm{~Pa} / \mathrm{cm}^{3} / \mathrm{s}$. Pre- and postoperative Anterior rhinomanometry values were recorded and shown in (Table 1).

\section{Discussion}

The fear regarding the effects of performing nasal surgery on the growing nose dated back to the 1950s, when Gilbert and Segal published their warning against resecting the quadrilateral cartilage, referring to it as a keystone in development of the cartilaginous vault [2]. Farrior and Connolly echoed the sentiment after a review of the literature in 1970, concluding that nasal surgery in children should be postponed till puberty [3].

Later studies on animals showed that a growing nasal septum could be corrected without affecting long-term growth; later studies on children began appearing, with promising results [9]. Most of the studies were on children with a severe deviation that encourage early correction.

Béjar et al. in the 1990s concluded to delay surgery for children with mild septal deviation till puberty [10]. Their optimum age was 16 years for boys and age 14 years for girls. However, they advocated early surgery on children as young as 6 years of age if they had a severe septal deviation causing severe functional problems. Crysdale and Walker [11] considered an external or open septorhinoplasty to be appropriate in children aged 6 years and older. However, Cristophel and Gross stated surgery can be performed on young children aged 5 years [1].

Recent studies have indicated that the delay in surgical correction of the deviated septum may cause children to develop misalignment of their dentition, abnormal facial growth, and worsening progression of their respiratory problems. Therefore, many surgeons now routinely perform septoplasty procedures in children who present with severe nasal septal deviation [12].

Nasal obstruction secondary to septal deviation may be detrimental to children. Studies examining the effect of impairment of nasal breathing due to nasal obstruction on maxillofacial development have shown that children with obligate mouth breathing secondary to nasal septum deviation have facial and dental anomalies compared to nasal breathing population. This suggests that not performing pediatric septoplasty may be more harmful for children with nasal obstruction [13]. 


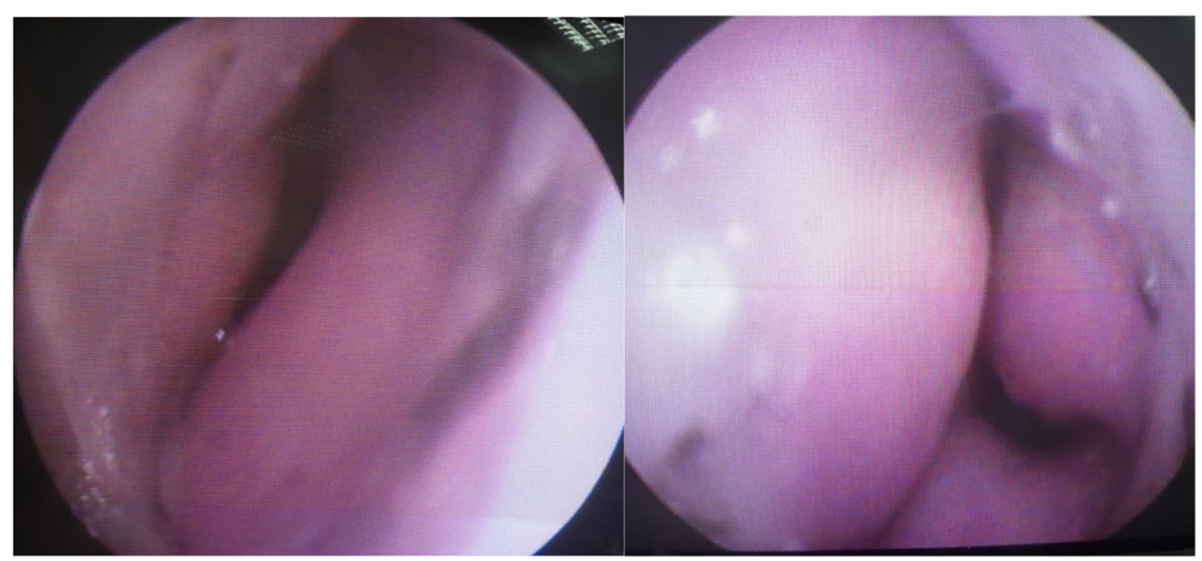

Fig. 5 Endoscopic pre-and postoperative view

In our study, patients underwent open septoplasty using the Modified Goldmann's technique. We used an open approach to provide more exposure in dealing with caudal septal deviations; in our technique, we also elevate a mucoperichondrial flap on one side and removed only a strip of caudal cartilage to straighten the caudal septum without interruption of the nasal growth centers.

Delaney et al. in 2018 also found that an open approach provides the exposure and access necessary to release extrinsic distorting forces on the septum to fully appreciate intrinsic septal deformities. Weaknesses or insufficiencies identified through this approach can be precisely corrected with grafts and sutures to maintain the septum in a midline position and support the external nose [14]. The current study revealed that open approach provided the exposure and access necessary to correct the caudal septal deviations.

In 1994, Giles et al. showed the great value of preserving the mucoperichondrium overlying the septal cartilage. However, in selected cases in with acutely deviated spur of septal cartilage abutting a turbinate or the lateral nasal wall causing nasal airway obstruction, the mucoperichondrium was resected without the need to elevate a flap from the septum [15]. The current study revealed that elevation of a mucoperichondrial flap on one side only is enough to enable the removal of a strip of caudal cartilage to straighten the caudal septum.
During the early postoperative visit at the 2nd week, there was significant decrease in the nasal obstruction and the NOSE scale score. Endoscopic assessment revealed that $35 \%$ of cases suffered from residual posterior septal deviation which did not cause significant obstruction. Twenty percent of patients suffered from nasal adhesions which is managed successfully by Vaseline nasal gauze day after day for successive 2 weeks. Also, 25\% complained of minimal external nasal deformity which did not affect their quality of life. Otherwise, there were no signs of septal hematoma or perforation.

During the last postoperative visit at the 3rd month, there was significant reduction on nasal resistance values on anterior rhinomanometry with objective improvement on the nasal function and quality of life.

It should be noted that the postoperative follow-up period was short regarding accurate assessment of the effect of growing nose on surgery

\section{Conclusion}

Open septoplasty in children using the modified Goldman's technique has enabled accurate approach for correction of nasal septal deviation especially those located in the caudal septal region.

The technique also offers a significant reduction of the nasal symptoms postoperatively with marked

Table 1 Pre and postoperative anterior rhinomanometry

\begin{tabular}{|c|c|c|c|c|c|c|c|c|c|c|c|}
\hline & \multicolumn{5}{|l|}{ Pre } & \multicolumn{5}{|l|}{ Post } & \multirow{2}{*}{$\begin{array}{l}P \\
\text { value }\end{array}$} \\
\hline & Mean & SD & Median & Minimum & Maximum & Mean & SD & Median & Minimum & Maximum & \\
\hline Inspiratory rhinomanometry & 0.41 & 0.17 & 0.40 & 0.10 & 0.80 & 0.26 & 0.11 & 0.25 & 0.10 & 0.50 & $<0.001$ \\
\hline Expiratory rhinomanometry & 0.57 & 0.23 & 0.60 & 0.10 & 1.00 & 0.31 & 0.15 & 0.30 & 0.10 & 0.60 & $<0.001$ \\
\hline
\end{tabular}

$P$ predictive value $=$ significant 
improvement of the nasal resistance and quality of life in severe cases of deviated nasal septum.

The technique has drawbacks in difficulty with dealing with posterior deviations and bony spurs. Also, the external deformity experienced by some patients postoperative must be put in concern, otherwise no major complication detected.

\section{Acknowledgements}

Not applicable.

\section{Authors' contributions}

All authors have read and approved the manuscript. A.N.- - writing the article and did surgeries; H.D.- - data collection and writing the article; M.A.—did surgeries and revision of data; O.S._-revision and adjustment of research; A.E.--revision and adjustment of research

\section{Funding}

None

\section{Availability of data and materials}

Data are available from the authors upon reasonable request with permission from Cairo University.

\section{Ethics approval and consent to participate}

This study was conducted in Cairo University Hospital after receiving the approval from the Research Ethics Committee. Reference number is not applicable. Written informed consents were obtained from all participants or from a parent or guardian for participants under 16 years old before enrollment.

\section{Consent for publication}

Not applicable.

\section{Competing interests}

The authors declare that they have no conflicts of interest.

Received: 14 July 2020 Accepted: 11 January 2021

Published online: 08 February 2021

\section{References}

1. Cristophel JJ, Gross CW (2009) Pediatric septoplasty. Otolaryngol Clin North Am 42:287-294

2. Gilbert JG, Segal S Jr (1958) Growth of the nose and the septorhinoplastic problem in youth. AMA Arch Otolaryngol 68:673-682

3. Farrior RT, Connolly ME (1970) Septorhinoplasty in children. Otolaryngol Clin North Am 3:345-364

4. D'Ascanio C, Lancione G, Pompa E, Rebuffini N, Mansi M (2010) Manzini, Craniofacial growth in children with nasal septum deviation: a cephalometric comparative study. Int J Pediatr Otorhinolaryngol 74: 1180-1183

5. Can IH, Ceylan K, Bayiz U, Olmez A, Samim E (2005) Acoustic rhinometry in the objective evaluation of childhood septoplasties. Int J Pediatr Otorhinolaryngol 69(April (4)):445-448

6. Stewart MG, Smith TL, Weaver EM, Witsell DL, Yueh B, Hannley MT, Johnson JT (2004) Outcomes after nasal septoplasty: results from the Nasal Obstruction Septoplasty Effectiveness (NOSE) study. Otolaryngol Head Neck Surg 130(3):283-290

7. Lawson W, Westreich R (2007) Correction of caudal deflections of the nasal septum with a modified Goldman septoplasty technique: how we do it. Ear Nose Throat J 86(10):617-621

8. Mladina R, Skitarelić N, Poje G, Šubarić M (2015) Clinical implications of nasal septal deformities. Balkan medical journal 32(2):137

9. McComb HK, Coghlan BA (1996) Primary repair of the unilateral cleft lip nose: completion of a longitudinal study. Cleft Palate Craniofac J 33:23-30

10. Béjar I, Farkas LG, Messner AH, Crysdale WS (1996) Nasal growth after external septoplasty in children. Arch Otolaryngol Head Neck Surg 122: $816-821$
11. Crysdale WS, Walker PJ (1994) External septorhinoplasty in children: patient selection and surgical technique. J Otolaryngol 23:28-31

12. Akkina SR, Parikh SR (2018) Pediatric septoplasty. Oper Tech Otolayngol Head Neck Surg 29(2):66-69

13. Anderson K, Ritchie K, Chorney JM, Bezuhly M, Hong P (2016) The impact of septoplasty on health-related quality of life in pediatric patients. Clin Otolaryngol 41(2):144-148

14. Delaney SW (2018) Evolution of the septoplasty: maximizing functional and aesthetic outcomes in nasal surgery. MJ Otol 1(1):004

15. Giles WC, Gross CW, Abram AC, Greene WM, Avner TG (1994) How i do it head and neck and plastic surgery a targeted problem and its solution: endoscopic septoplasty. Laryngoscope 104(12):1507-1509

\section{Publisher's Note}

Springer Nature remains neutral with regard to jurisdictional claims in published maps and institutional affiliations.

\section{Submit your manuscript to a SpringerOpen ${ }^{\circ}$ journal and benefit from:}

- Convenient online submission

- Rigorous peer review

- Open access: articles freely available online

- High visibility within the field

- Retaining the copyright to your article

Submit your next manuscript at $>$ springeropen.com 